\title{
La guerra como respuesta a la crisis de los ingresos señoriales en el Reino de Navarra durante el reinado de Carlos II (1349-1387) *
}

Jon Andoni Fernández de LarRea y Rojas **

Más que en ningún otro período, la guerra fue uno de los mayores componentes de la vida de los hombres en los siglos finales de la Edad Media, afectando profundamente a todos los aspectos de la existencia. Es por ello una especie de atalaya desde la cual pueden observarse muchos y variados aspectos de la vida y sociedad medievales. El Reino de Navarra no fue ajeno a todo ello, es más, el particular contexto en el que se vio envuelto le llevó a sufrir en sí mismo la terrible experiencia de la guerra en numerosas ocasiones durante el reinado de Carlos II, en veinticinco de los treinta y ocho años de reinado se registra algún tipo de actividad militar.

Saliendo de la historia de las batallas y de las operaciones militares, que constituían su antiguo objetivo de trabajo, la historia militar se ha insertado en el movimiento general de renovación de las ciencias históricas, que en este campo del estudio de la guerra y los ejércitos medievales impulsó $F$. Lot desde mediados de los años cincuenta '.

\footnotetext{
* Comunicación presentada al I Congreso Internacional de Historia de los Pirineos. Cervera. Noviembre 1988.

* Universidad del País Vasco.

$1 \mathrm{PH}$. Contamine, Guerre, état et société à la fin du Moyen Age. Etudes sur les armées des rois de France, 1337-1494, París y La Haya, Mouton, 1972, pág. V. A. MARTEL, «Le renouveau de l'histoire militaire en France", Revue Historique, núm. 497, 1971, pág. 107.
} 
La propuesta de Lot, desarrollada desde el inicio de la década de los setenta con Ph. Contamine, sugiere estudiar no sólo el arte militar y la organización de los ejércitos, sino también analizar a los hombres que los forman en sus orígenes sociales y geográficos, sus carreras, sus actividades, los lazos que les unen. Se presta una atención creciente a las motivaciones de individuos y sociedades para hacer la guerra, a los intereses y mentalidades colectivas o particulares ${ }^{2}$. Predomina una tendencia a la historia social, al estudio de los caracteres del mundo guerrero, a explicar unos comportamientos. Comportarnientos que no pueden desligarse del marco general de la crisis de la sociedad feudal.

En principio, la prestación del servicio militar por parte de la nobleza en el Reino de Navarra era de carácter obligatorio, regulada por las normativas del Fuero General, aunque durante el reinado de Carlos II se empleó preferentemente el servicio de voluntarios pagados ${ }^{3}$. Este servicio se presta, generalmente, a caballo, así lo reclaman las concesiones de caballerias y mesnadas ${ }^{4}$ :

«... teniendose siempre apeiado de cauaillo et armas como a mesnadero pertenesce para nuestro seruito..."

Quien asi lo hace, o al menos se mantiene dispuesto a hacerlo poseyendo caballo y armas, queda excusado de ciertas obligaciones fiscales, como los hidalgos de Tudela en $1353^{5}$ :

${ }^{2} \mathrm{PH}$. Contamine, Guerre..., págs. VI-VII, X-XI; "L'histoire Militaire et l'histoire de la Guerre dans la France médiévale depuis trente ans", Actes du 100e Congres National des Sociétés Savantes. Paris 1975. Tendences, perspectives et méthodes de l'histoire médiéval, París, Secretariat dÉtat aux Universités, 1977, pág. 88-89. A. MARTEL, obra citada, pág. 113. A. CORVIS!ER, "L'étude de la guerre entre la sociologie et l'histoire", en Revue Historique, núm. 522, 1977, pág. 361-364.

${ }^{3}$ Fuero General de Navarra, Libro I, Título II, Capítulo I. J. A. FZ. DE LARREA, Cambios en el sistema militar navarro durante el reinado de Carlos II, Vitoria-Gasteiz 1987 (Memoria de Licenciatura inédita), págs. 136 y ss.

${ }^{4}$ Archivo General de Navarra, Caj. 11, núm. 90; J. R. CASTro, Catálogo del Archivo General de Navarra. Sección de Comptos-Documentos, tomo Il, Pamplona, Diputación Foral de Navarra, 1952, núm. 448.

${ }^{5}$ AGN Reg. 74, J. J. URANGa, "Documentos sobre la población de Navarra en la Edad Media. El libro del monedaje de Tudela de 1353", Principe de Viana, núm. XXII, Pamplona 1961, págs. 137-176, y Príncipe de Viana, núm. XXIII, Pamplona 1962, págs. 243-306, pág. 285. 
«Estos dizen que deuen ser escusados de pagar monedage por razón que mantienen cauaillos et armas segund lur priuilegio

Johan Sánchiz de Cadreita

Johan Xeméniz de Castillón

Sancho d'Aluaro»

Pero esto no era norma universal, al menos en los primeros años del reinado de Carlos II, algunos nobles navarros todavía prestaron servicio a pie, al igual que otros muchos de los hidalgos del Norte del Reino de Castilla ${ }^{6}$. Así en la expedición que marchó a Normandía en el verano de 1353 los hay en las compañias de Martín Martíniz d'Uriz y de Salt d'Ostabarets $^{7}$. Con posterioridad todo noble que preste servicio en los ejércitos del Rey de Navarra, e incluso algunos no nobles, lo hará a caballo, como hombre de armas.

Es posible observar cómo a lo largo de todo el período de estudio, 1349-1387, se produjo un aumento de los efectivos montados en el seno de las fuerzas militares navarras, lo cual prácticamente equivale a decir incremento de la presencia de miembros de los grupos nobiliarios. Este ascenso es más importante en cuanto que no es sólo un incremento en términos absolutos sino también en términos relativos, pues paralelamente se va registrando un descenso o estancamiento de las fuerzas de a pie. Este incremento de los efectivos moniados no sólo se registra entre los hombres de armas, sino que también se ve favorecido por el alistamiento de arqueros montados y pillarts, pero que no han sido tenidos en cuenta a la hora de efectuar el análisis de esta cuestión por tratarse fundamentalmente de tropas extranjeras, alistadas en escaso número las primeras y sólo en una ocasión los segundos, lógicamente tampoco hemos contabilizado para ello a los numerosos hombres de armas de las compañías extranjeras, a pesar de lo cual el incremento sigue siendo significativo ${ }^{8}$.

Tras contemplar estos datos se nos plantea un interrogante, ¿cuál es la razón de este incremento?, ¿por qué precisamente en este mo-

6 P. LOPEZ de Ayala, Crónica del Rey don Pedro /, Madrid, Biblioteca de Autores Españoles, 1953, pág. 552.

${ }^{7}$ AGN Caj. 12, núm. 23, XXIX; CASTRO, II, núm. 600.

8 J. A. FZ. DE LARREA, obra citada, págs, 69 y ss.

En 1355 se alistaron 219 hombres de armas y 1.571 hombres de a pie; en junio de 1368 eran ya 474 hombres de armas, 7 arqueros y 751 hombres de a pie; finalmente, en 1379,796 hombres de armas, 496 pillarts, 14 arqueros y 761 hombres de a pie. 
mento los nobles acuden cada vez más al servicio militar?, un servicio militar que en estos años se ha transformado en voluntario y pagado. Desde tiempos anteriores existía la tradición de que los segundones de las familias nobles, por lo general sin posibilidad de acceso a la parte más sustanciosa de la herencia, buscasen posición y fortuna mediante una carrera en la Iglesia o en el servicio a la monarquía, en la guerra o la administración ${ }^{9}$.

Sin embargo, la explicación más convincente se halla en relación con la crisis que afectó a la sociedad europea occidental en los siglos finales de la Edad Media, y en especial con el descenso del nivel de renta de los grupos nobiliarios. Este descenso obligaría a los señores a buscar respuestas que les permitieran mantener sus ingresos, teniendo en la guerra una apreciable fuente de beneficios en la forma de soldadas, botín, saqueos, mercedes y recompensas, o como medio de acceder a una carrera en la administración y la corte.

El descenso del nivel de renta de los grupos señoriales del Reino de Navarra nos es conocido fundamentalmente a través de medios indirectos, los más reveladores son los datos que sobre endeudamiento nos ofrecen los registros del sello de la sección de Comptos del Archivo General de Navarra. A continuación veremos unos ejemplos ilustrativos de la anterior afirmación.

Sabemos cómo el 13 de de abril de 1350 los hermanos Arnaut Guillem y Arnaut Arremón de Agramónt, ricoshombres de Navarra, se vieron obligados a pedir a dos comerciantes pamploneses, Martín y Johan de Galart, un préstamo de 145 escudos franceses, pagaderos el 11 de noviembre del mismo año ${ }^{10}$. El 24 de mayo de 1362, el Tesorero del Reino ordenó al guarda del peaje de Estella que entregase a Bertrand d'Agramont, por lo que podía debérsele de sus mesnadas, 10 libras de carlines prietos, para liberar una cinta de plata que el señor joven de Agramont empeñó en la hostelería del Caballo Blanco de Pamplona ${ }^{11}$; lo más grave no es que el señor joven de Agramont se viese obligado a empeñar la cinta de plata, sino que necesitara la ayuda del Tesoro del Reino para

${ }^{9}$ A este respecto es muy interesante la obra de G. Duby, Guillermo el Mariscal, Madrid, Alianza Editorial, 1985.

${ }^{10}$ B. Leroy, Historia del Reino de Navarra, San Lorenzo de El Escorial, Swan, 1986, pág. 154.

11 AGN Caj. 15, núm. 92, II; CAStro, IV, núm. 190. 
recuperarla. El 18 de diciembre de 1365, Johan Sánchiz d'Ureta, escudero, su esposa y fiadores, fueron condenados a instancias de Guillem de la Haya, Preboste de la Navarrería, por impago de una suma de 29 libras y 10 sueldos carlines prietos ${ }^{12}$.

En la mayor parte de los casos los prestamistas pertenecen a la comunidad judia, como podemos observar a continuación. El 17 de diciembre de 1368, Alfonso Díaz de Morentín se endeudó con el judío tudelano Salomón d'Ablitas por la cantidad de 6 libras y 1 sueldo prieto, pagaderas en un año a partir de la fecha ${ }^{13}$. Sancho Gil d'Azagra, caballero, obtenía el 11 de enero de 1369 un préstamo de 40 libras y 10 sueldos de Gento Embolat, judío de Estella, págadero en San Juan de junio ${ }^{14}$. Los ejemplos podian prolongarse a lo largo de varias páginas.

Otras de las referencias indirectas que nos indican el malestar económico que pesaba sobre los nobles navarros, aunque pueda ser menos significativo, es el abandono de la costumbre de armarse caballero. Es cada vez más frecuente que los hijos de las familias nobles permanezcan en el rango de escudero, a pesar de lo cual no tenian ningún inconveniente para ejercer una carrera en la administración o las fuerzas armadas. La onerosa ceremonia de armar caballero hacía sentir su peso en una época de crisis ${ }^{15}$, así que la dignidad de caballero comenzó a restringirse a aquellos que podían gastar su dinero en ella $o$ a quienes accedian por honor o recompensa real por los servicios prestados, como Pedro Sánchiz de Cascant en $1355^{16}$.

Si a todo lo anteriormente enunciado añadimos el torrente de gastos que suponia el llevar una vida adecuada a lo que se entendía como el ideal de nobleza, con todo lo que ello implicaba de gastos suntuarios, residencia, las nuevas y perfeccionadas formas de armaduras, los costosos caballos, los regalos, las limosnas y medios económicos para asegurarse un buen lugar en el más allá ${ }^{17}$, entonces, podemos imaginar la

12 AGN Caj. 19, núm. 40, fol. 70v.

${ }^{13}$ AGN Caj. 171, núm. 16, LI.

14 AGN Caj. 171, núm. 16, XXXIX.

15 M. KeEn, La caballeria, Madrid, Ariel, 1986, pág. 193. Para conocer los detalles de esta ceremonia ver M. KEEN, obra citada, pág. 92-114, y R. LLULL, Libro de la orden de caballería, Barcelona, Alianza Editorial, 1986, págs. 55-61.

16 AGN Caj. 54, núm. 60; CaSTRO, II, núm. 731.

17 M. KEEN, obra citada, págs. 205-207. B. LeRoY, obra citada, págs. 153-154. 
presión que las dificultades económicas ejercieron sobre los nobles návarros.

Como hemos visto, la situación podía llegar a ser preocupante en ciertos casos, ¿qué respuestas podían dar a ella los nobles? No se pretende analizar aquí todos aquellos medios de los cuales se valieron los grupos nobiliarios para incrementar su volumen de rentas, solamente examinaremos uno, la guerra y el servicio militar como fuentes de beneficios económicos y ascenso social en la Navarra de Carlos II.

En primer lugar hay que dejar claro como en muchos casos el servicio de armas puede estar unido a una carrera en la administración, utilizándose como un sólido apoyo para ésta a la hora de ganar méritos ante el monarca, cosa que no sólo harán los nobles. La opinión generalizada en los siglos finales de la Edad Media era ver a la guerra como un medio digno de adquirir riquezas y honores, e incluso se animaba a los jóvenes, en especial de la baja nobleza, a que buscaran en ella, tanto en su país como en el exterior, un medio de promoción económico y social ${ }^{18}$.

De entre los beneficios que los nobles navarros podían obtener de la guerra indicaremos en primer lugar las rentas que la monarquía asignaba, tanto en tiempo de paz como de guerra, a los ricoshombres, caballeros y escuderos, para estar dispuestos en cualquier momento a prestar servicio armado. Bajo la denominación de caballerías y mesnadas, el Rey asignaba rentas de 20 libras anuales a miembros de la nobleza, a cambio de las cuales esperaba la prestación de un servicio por parte del beneficiario de 40 dias anuales a sus propias expensas como hombre de armas, la única diferencia entre ambas residia en que las caballerias se asignaban a ricoshombres y barones, mientras que las mesnadas lo eran a caballeros y escuderos. Era frecuente que un noble pudiera ser beneficiario de más de uno de estos feudos de renta, lo cual en el caso de los ricoshombres sucedía siempre, debiendo estar obligado a prestar servicio con tantos hombres de armas como caballerías o mesnadas disfrutase. Según vaya pasando el tiempo las mesnadas dejaran de ser una fuente apreciable de ingresos, sobre todo frente a otros recursos provenientes de la guerra, como las soldadas mensuales, según la moneda navarra se vaya depreciando. Así, mientras en 1362 eran

${ }^{18}$ M. KEEN, obra citada, págs. 203-206, 299. 
necesarios al menos tres mieses de soldada para obtener los mismos beneficios que con una mesnada, en 1378 bastaba con un solo mes, con el añadido de que las soldadas se asignaban en moneda de oro, por lo general en florines ${ }^{19}$.

En la misma línea de las anteriores podemos situar las rentas provenientes de las alcaidías de los castillos, con el agravante de ser todavía más exiguas. Las rentas de las guardas de los castillos oscilaban entre los 20 sueldos y 5 cahices de trigo del alcaide de Oro y las 8 libras y 40 cahices de los alcaides de Toloño y de Assa, cantidades todas ellas anuales ${ }^{20}$. La inmutabilidad de dichas rentas a lo largo del reinado de Carlos II provocará su pérdida de importancia frente a las más jugosas que se obtenían de las capitanías de las villas, que el Rey otorgaba en período de guerra, o de la guarda de determinados castillos de posesión conflictiva. De esta forma la renta que recibía Rodrigo d'Uriz como capitán de Vitoria en el año 1369 era de 100 florines mensuales, la de Johan Ruiz d'Ayuar como capitán de Logroño en el mismo año ascendía a 50 florines mensuales, la de Ramiro d'Areyllano cuando se hizo cargo de la misma se incrementó hasta 150 florines al mes ${ }^{21}$, y la de Johan Ramírez d'Areyllano como guarda del castillo de Zaldiaran en 1370 fue de 60 florines mensuales ${ }^{22}$. Estas cifras no deben de inducirnos a error, se trata de las principales posesiones adquiridas por el Reino navarro en 1368, directamente amenazadas por las fuerzas de Enrique II de Castilla, y asignadas a miembros de la alta nobleza; en este mismo período el guipuzcoano Miguel Yuaynnes d'Urquiolla recibía por la guarda de una fortaleza menos importante, la villa de Alegría de Alava, una renta de 10 libras de carlines prietos y 30 cahices de trigo anuales ${ }^{23}$, una renta escasamente superior a otras alcaidías de castillos.

Con el envío de tropas a guarnecer las plazas normandas de Carlos II en 1353, comenzaron las tropas navarras a recibir sus primeras soldadas ${ }^{24}$; pagadas prácticamente siempre en moneda de oro, escudados o florines, van a convertirse en uno de los principales atractivos de

${ }^{19}$ AGN, Caj. 15, núm. 54, V; CAStro, IV, núm. 424. AGN, Caj. 34, núm. 17, XXV; CASTRO, XI, núm. 659.

${ }^{20}$ AGN, Reg. 90 , fols. 40 a 43 .

21 AGN, Reg. 131, fols. 98 a 99,137 a 142.

${ }^{22}$ AGN. Reg. 135, fol. 91r.

${ }^{23}$ AGN, Caj. 38, núm. 35, III; CASTRO, VII, núm. 1.040

${ }^{24}$ AGN, Caj. 12, núm. 22, XIII; CASTro, II, núm. 551. AGN, Caj. 12, núm. 14; CaStro, II, núm. 559. 
la guerra para los nobles navarros. Sobre las mesnadas, junto a la ventaja de ser pagadas en moneda fuerte añaden la de no permanecer estáticas, sino que varían según la coyuntura económica adaptándose a ésta, sin fosilizarse como los anteriores feudos de renta. Asimilables a las soldadas son las primas concedidas por alistamiento o por embarque hacia Normandia, como en 1364 cuando fueron pagados 5 florines como prima de enganche a los combatientes y otros 4 florines a aquellos que embarcaron para Cherbourg a finales de julio ${ }^{25}$. Más informalmente podía concederse ese dinero a algunos combatientes a título individual, como a los hermanos Martín y Michelco de Larramendi, que en 1358 querian marchar a servir al Rey en Normandia ${ }^{26}$.

Otro de los atractivos de la guerra era la perspectiva del botín y los rescates, cuyos beneficios podían superar con mucho los de las soldadas. Desde el punto de vista de la mentalidad medieval es completamente justo que el vencedor se apodere de los caballos y armas de su prisionero, era el botín, una especie de compensación económica por los peligros padecidos. Pero de buscar el botín como compensación a buscar el botín por el botín, siendo además una época de crisis, la distancia era reducida y fue superada con facilidad ${ }^{26}$ bis. Al ser todos estos beneficios de carácter privado únicamente nos ha llegado un documento referente a ellos entre los fondos del Archivo General de Navarra. Se trata de una orden del Delfin Carlos, regente del Reino de Francia, a sus oficiales para que permitan el paso libre, con sus caballos y sus mercancías, a todos los soldados, navarros u otros, que portasen una carta de Carlos II o de su hermano, el infante Luis ${ }^{27}$; fechada el 30 de septiembre de 1359, sin duda hace referencia al botín conseguido por los navarros y gentes de las compañías al servicio de Carlos II en las luchas de Normandie e lle-de-France entre los años 1355 y 1359, pero sobre todo en el último año de la guerra, entre agosto de 1358 y agosto de 1359 .

Los rescates también estaban considerados como perfectamente legítimos, un combatiente podía exigir a su prisionero una suma de dinero

${ }^{25}$ AGN, Caj. 18, núm. 132, XXXI; CASTro, V, núm. 358. AGN, Caj. 18, núm. 132, XXXV; Castro, V. núm. 359. AGN, Caj. 18, núm. 131, XXIII; Castro, V, núm. 480. M. LaRRayoz, "Eco de la batalla de Cocherel en los documentos de Comptos reales de Navarra", Príncipe de Viana, núms. 96-97. Pamplona 1964, pág. 253 y ss.

${ }^{26}$ AGN, Reg. 86, fol. 112v.

${ }_{26} 6$ bis M. KEEN, obra citada, pág. 301. Varios Autores, La guerre au Moyen Age. CNRS Pons, 1976, págs. 99-100.

${ }^{27}$ AGN, Caj. 13, núm. 212; CASTro, III, núm. 381. 
a cambio de la cual conseguía su libertad, cantidad que sería más elevada cuanto mayor fuera el linaje y la fortuna del prisionero. Lo más frecuente era que las autoridades superiores de los combatientes se reservasen el derecho a quedarse con los prisioneros de mayor valor a cambio de una recompensa en metálico para el captor, disposición recogida en el Fuero General de Navarra ${ }^{28}$. Esta costumbre nos ha permitido recibir una mayor información para este punto, fundamentalmente para los años 1367, batalla de Nájera, y 1378-1379, la guerra contra Castilla. De los rescates de la guerra contra Castilla los beneficiarios fueron Jean de Pommiers, señor de Lascuyn, que recibió del Tesoro de Navarra 500 florines por cinco caballeros aragoneses ${ }^{29}$ : Tristán, hermano del vizconde de Castellbó, obtuvo 900 florines por el rescate de Johan de Sada, que el Rey tomó para si ${ }^{30}$; finalmente, Miguel García de Galdiano se embolsó 82 florines por dos prisioneros de la villa de Mendigorría que el Rey tomó "a nuestra mano" ${ }^{31}$. Del caso del que mayor información disponemos es del rescate de Johan Vélaz de Guevara, hijo de Beltrán Vélaz de Guevara, un guipuzcoano al servicio de Enrique de Trastámara pero que ya lo había estado antes al de Carlos II, que fue capturado en el campo de batalla de Nájera por el navarro Miguel Périz de Ciriza, escudero. Mediante escritura fechada en Vitoria el 9 de julio de 1368 se ajustó la cuantía del rescate en 1.000 doblas de oro ${ }^{32}$ y actuando como fiadores del Guevara, Johan Martíniz de Ciordia, Sancho Gil d'Azagra y García Miguel d'Elcart. Al no hacerse efectivo el pago del rescate, los bienes de los fiadores se vieron en peligro de ejecución en diciembre del mismo año; el 28 de marzo de 1369, las posesiones de Beltrán Vélaz de Guevara en Navarra (villas de Etayo, Oco y Riezu, los montes de Granada y la pecha de los labradores de Izurda, Muniain, Azcona, Arizaleta, Murugarren, Alloz, Lácar, Lezaun e Irujo por no ir a trabajar la viña de Riezu) fueron vendidas por el portero, Miguel García de Lizasoain, en 1.150 libras al propio Miguel Périz de Ciriza, para abonar el rescate de Johan Vélaz de Guevara ${ }^{33}$. Como podemos observar por éste y otros casos sucedidos en otros reinos ${ }^{34}$, el

${ }^{28}$ FGN, I, I, IX.

${ }^{29}$ AGN Reg. 161, fol. 110. AGN Caj. 39, núm. 29, X; CASTRO, XII, núm. 586.

${ }^{30}$ AGN Reg. 161, fol. 139r.

${ }^{31}$ AGN Reg. 161, fol. 138v. AGN Caj. 35, núm. 35, II; CASTRO, XII, núm. 166.

${ }^{32}$ AGN papeles sueltos, legajo 167, carpeta II.

${ }_{33}$ AGN Caj. 25, núm. 10; CASTRO, VII, núms. 400 y 578. AGN Caj. 25, núm. 96; CASTRO, VII, núms. 400 y 583 .

${ }^{34}$ Para conocer las consecuencias que la bataila de Nájera tuvo para ciertos nobles aragoneses que lucharon junto a Enrique de Trastámara, ver A. GUTIERREZ DE VELASCO, "LOS ingleses en España. Siglo XIV", en Estudios de la Edad Media de la Corona de Aragón, tomo IV, Zaragoza 1951, págs. 215-319. 
cobro de los rescates se llevaba hasta las últimas consecuencias, llegando a arruinar en algún momento a la familia de ciertos prisioneros.

Otra de las posibilidades económicas de la guerra era la obtención de una renta o donación real por los servicios prestados en una campaña o por algún acto destacado durante éstas. En algunas ocasiones adoptaba la forma de la donación de un feudo de renta, es decir una mesnada, como las ocho concedidas el 24 y 25 de octubre de 1355 en Evreux ${ }^{35}$ :

«... specialment en esta vez que partiemos de nuestro dicto regno por venir por mar en nuestra tierra de Normandia..."

En un nivel superior, por los servicios prestados en la misma expedición, el alférez Martín Enríquiz de Lacarra recibió los molinos del Rey en Saint Jean-Pied-de-Port, en el río Ugarra, y la villa de Mongelos ${ }^{36}$. Lo más frecuente era obtener una cantidad en metálico o una renta anual, en dinero o especie. Como ejemplo de las rentas en metálico podemos hablar de las 100 libras anuales concedidas a Arnalt Lup, señor de Lucxa, en 1361, por los servicios prestados durante la guerra en Cotentin ${ }^{37}$, o la de 120 libras de carlines prietos anuales por los servicios prestados, en especial en la entrada en Logroño, habiendo sido el señor de Lucxa el primero en poner la bandera y tomar posesión de la villa, puente y fortaleza por el Rey de Navarra ${ }^{38}$. Entre las rentas en especie tenemos el caso de los 50 cahices de trigo anuales entregados a Rodrigo d'Ubago, sargento de armas, porque en 1379 cuando los castellanos desampararon la villa de Falces, que estuvo cierto tiempo en sus manos, se apoderó del castillo con ciertos compañeros, lo fortificó y lo guardó bien y lealmente ${ }^{39}$. Como muestra de las cantidades donadas a una vez tenemos los 200 florines que el 16 de febrero de 1379 recibió Jean de

${ }^{35}$ AGN Caj. 12, núm. 97; CASTRO, II, núm. 723. AGN Caj. 12, núm. 99; CASTRO, II, núm. 725. AGN Caj. 34, núm. 84, I; CASTRO, II, núm. 726. AGN Caj. 12, núm. 100; CASTRO, II, núm. 727. AGN Caj. 12, núm. 147; CASTRO, II, núm. 728. AGN Caj. 12, núm. 103; CASTRO, II, núm. 731. AGN Caj. 12, núm. 104; CASTRO, II, núm. 732.

${ }^{36}$ AGN Caj. 12, núm. 96; CaStro, II, núm. 722. AGN Caj. 12, núm. 72; CaStro, II, núm. 733.

37 AGN Caj. 41, núm. 16; CASTro, III, núm. 495.

${ }^{38}$ AGN Caj. 23, núm. 14; CASTro, VII, núm. 119. AGN Caj. 19, núm. 40, fol. 9 r.

${ }^{39}$ AGN Caj. 40, núm. 30, II; CASTRO, XII, núm. 1.051. 
Pommiers, señor de Lascuyn, por los buerios servicios prestados durante la guerra castellana ${ }^{40}$, o los 120 florines concedidos a García Lópiz d'Arbiçu, por la peligrosidad de la zona en la que se mantenía con 50 hombres, una vez que la villa de Echarri-Aranaz cayó en manos de los castellanos durante la misma guerra ${ }^{41}$. También podía dar el soberano, a aquellos que por sus cualidades o cualquier otro motivo, ejercian un papel importante durante las hostilidades, una cantidad para mantener su estado, como en la guerra castellana de 1378-1379 recibieron Martín Martíniz d'Uriz, 50 florines mensuales ${ }^{42}$, o Lope, señor de Sant Julián, 80 florines al mes ${ }^{43}$. A esto último tenían mucho más fácil acceso aquéllos que por su elevado rango o experiencia militar tuviesen a su cargo un mayor y más escogido grupo de tropas, siendo los beneficiarios del rendimiento de éstas de cara a la obtención de favores reales.

Pero los nobles navarros no sólo confiaban en los beneficios ocasionales de la guerra, los ejércitos no eran permanentes, el estado quedaria agotado de ser asi, el servicio de armas trataba de combinarse con una carrera en la administración o el servicio en la corte. Un puesto en los hostales de la familia real podía permitir obtener el favor de algún miembro de ésta, un buen padrino para el porvenir. Los cargos de sargento y ujier de armas proporcionaban unos ingresos anuales de 120 libras $^{44}$; los merinos recibían a su vez 100 libras anuales, excepto los dos merinos de las Montañas, en las partidas de Larraun o de Echarri-Aranaz, que ingresaban 50 libras cada uno, el castellano de Saint Jean-Pied-de-Port recibía 80 libras anuales ${ }^{45}$, aunque estos últimos puestos eran de más difícil acceso a quienes no perteneciesen a una familia de la nobleza alta o media alta. En la cima de los puestos de la administración con atribuciones militares se hallaban la alferecía y la lugartenencia de gobernador; la primera estuvo en manos de ramas bastardas de las casas reales de Navarra durante el reinado de Carlos II, hasta 1368 el cargo fue ocupado por Martín Enriquiz de Lacarra, descendiente del rey Enrique I por línea bastarda, quien recibía 500 libras por los gajes de la alferecía, más 120 libras

\footnotetext{
${ }^{40}$ AGN Caj. 35, núm. 46, III; CASTro, XII, núm. 272.

${ }^{41}$ AGN Caj. 34, núm. 11, X; CASTRO, $\mathrm{XI}$, núm. 660.

${ }^{42}$ AGN Caj. 38, núm. 1; CASTRO, XI, núm. 457.

${ }^{43}$ Ibidem.

${ }^{44}$ AGN Caj. 87, núm. 100, IV; CASTro, IX, núm. 983. AGN Caj. 30, núm. 41; CaStro, X,

${ }^{45}$ AGN Reg. 144 , fol. 85 r a 87 r. AGN Reg. 151, fol. 45
} núm. 449. 
por 6 caballerías y otras 300 libras por 15 mesnadas ${ }^{46}$, en total 920 libras anuales, desde 1379 el puesto recayó en Charlot de Beaumont, bastardo del Infante Luis, cuyos gajes ascendian a 2.000 libras anuales ${ }^{47}$. El cargo de lugarteniente de gobernador no dispone de una retribución fija, entre 1351 y 1357, Gil García d'laniz recibia 3 libras diarias, que hacian 1.095 libras al año ${ }^{48}$, mientras que en 1371 Martín Martíniz d'Uriz cobraba gajes de 20 sueldos (1 libra) diarios, que suponian 365 libras al año ${ }^{49}$.

Pero no todo suponía beneficios en la guerra para los nobles navarros, los gastos, el riesgo de ser hecho prisionero y la muerte también hacian sentir su presencia. Hay que recordar como el equiparse de caballo y armas era algo que corría a cuenta del propio combatiente, y ésto era cada vez más caro ${ }^{50}$. Para poder hacer frente a los costes del equipamiento no era infrecuente que se necesitase una ayuda del Tesoro Real. Esta ayuda podía conseguirse de dos formas, recibiendo el combatiente una cantidad variable de dinero para aparejarse o, más raramente, siendole entregadas directamente piezas de armadura o el arnés completo. La cuantía de las ayudas en metálico no corresponde a una tasa fija, oscilan entre los 30 sueldos entregados a Simonet de Mussy en $1363^{51}$ y las 160 libras que recibió Martín, señor de Domezain, en $1378^{52}$; a título indicativo, un arnés completo podia costar en 1383-1384 entre 70 y 74 florines (de 94 libras y 1 sueldo a 99 libras y 18 sueldos) ${ }^{53}$. Estas donaciones eran más frecuentes en vísperas de conflictos como antes de la expedición a Albania ${ }^{54}$ o en los preparativos de la guerra castellana de 1378-

${ }^{46}$ AGN Reg. 86, fol. 41.

47 AGN Caj. 47, núm. 22, IV; CASTRO, XV, núm. 107.

${ }^{49}$ AGN Reg. 65, fol. 40. AGN Reg. 83, fol. 103. J. ZABALO, La administración del reino de Navarra en el siglo xiv, Pamplona, Universidad de Navarra, 1973, pág. 60.

${ }_{49}$ AGN Reg. 139, fol. 139. J. Zábalo, obra citada, pág. 60 .

${ }^{50}$ Así lo especifican las condiciones de concesión de las mesnadas (AGN, Caj. 12, núm. 99; CASTRO, II, núm. 725):

“...teniendo se appareyllado de cauayllo et armas para nuestro seruito cada cuando requerido sera..."

M. KEEN, obra citada, págs. 296-297.

${ }_{51}$ AGN. Caj. 17, núm. 7, I; CASTRO, IV, núm. 1.205.

52 AGN, Caj. 36, núm. 51; CASTRO, XI, núm. 277.

${ }^{53}$ AGN, Caj. 28, núm. 47, I; CAStRo, XV, núm. 28. AGN, Caj. 47, núm. 62, IV; CASTRO, XIV, núm. 604.

${ }_{54}$ Para aparejarse con vistas al viaje a Albania, Rifflart de Polchai, Garro y Miguel de Galdiano recibieron 60 florines por cabeza (AGN, Reg. 152, fol. 18v). 
$1379^{55}$, e incluso una vez declaradas las hostilidades, como en 1363, durante la guerra con Aragón ${ }^{56}$, y en 1384-1385, con motivo de la guerra portuguesa ${ }^{57}$.

Por lo que se refiere a los caballos podemos decir lo mismo, se trataba de un regalo frecuente entre las mercedes de los monarcas, muy apreciado por su elevado coste económico. Al igual que las ayudas para armarse podía ser entregado directamente al combatiente, como cuando en 1375 el bastardo de Armagnac recibió un corcel valorado en 198 libras de carlines negros ${ }^{58}$, o entregarse una cantidad que cubriese en parte 0 en todo el coste del animal, como los 160 florines entregados en 1378 al señor de Agramont y su hijo, para adquirir dos corceles ${ }^{59}$.

Hemos visto anteriormente como uno de los beneficios que se podían obtener de la guerra provenían del rescate de prisioneros y la captura de su equipo y monturas, pero en la otra cara de la moneda estaba el peligro de ser hecho prisionero y convertirse en víctima de lo que antes era ganancia. La pérdida de cabalgaduras y arneses de guerra era compensada por el Tesoro del Reino cuando ésta se hubiese sufrido en servicio del Rey, como es el caso de Huet Durant, que recibió dos ayudas, de 50 y 34 florines, en compensación por un arnés perdido en Logroño y para poder así equiparse para la cabalgada contra Soria en $1378^{60}$. Los rescates de los prisioneros, al contrario, corrian por cuenta de la fortuna del propio combatiente, aunque podia obtenerse alguna ayuda real cuando la monarquía necesitaba con urgencia gentes de armas y le convenía acelerar la liberación de los prisioneros. Así sucedió en los primeros días de julio de 1378, cuando Pero Manrique, Adelantado de Castilla, capturó a traición en Logroño a un elevado número de tropas al servicio del Rey de Navarra, quien rápidamente concedió ayudas a sus capitanes para facilitar la liberación de sus gentes de armas. Fueron entregados 600 florines a Monuot de Bagues, otros 600 al señor de Osserayn, 400 florines al señor de Camer (se trataba del joven señor de

${ }^{55}$ AGN, Caj. 35, núm. 83, V; CAStro, XI, núm. 238. AGN, Caj. 36, núm. 51; CAStro, XI, núm. 277. AGN, Caj. 36, nüm. 10, V; CASTRO, XI, núm. 323.

${ }^{56}$ AGN, Caj. 17, núm. 7, II; CASTRO, IV, núm. 1.078. AGN, Caj. 17, núm. 7, I; Castro, IV, núm. 1.205. AGN, Caj. 17, núm. 20, XX; CASTRO, IV, núm. 1.309.

${ }_{57} A G N$, Caj. 29, núm. 47, I; CASTRO, XV, núm. 28. AGN, Caj. 49, núm. 59, I; CASTro, $X V$, núm. 1.017.

${ }^{58}$ AGN, Caj. 87, núm. 82, I; CASTro, IX, núm. 673.

59 AGN, Caj. 36, núm. 51; CASTRO, XI, núm. 277.

${ }^{60}$ AGN, Caj. 36, núm. 24, IV; CASTRO, XI, núm. 497. AGN, Caj. 36, núm. 52, III; CASTro, $\mathrm{XI}$, núm. 909. 
Agramont), 200 florines al señor de Lucxa, 400 florines a Gaillart d'Aspremont y 480 florines a los escuderos del bastardo de Armagnac ${ }^{61}$.

Otra de las cosas que traían consecuencias negativas era la deserción, que no sólo hacía perder los ingresos procedentes de la Hacienda Real, sino que cubria al desertor con un estigma de deshonor de cara a la sociedad. No parecen haber sido muy abundantes, sólo disponemos de noticias en dos ocasiones, en la primera de ellas tenemos la deserción de Alfonso García de la Serna y Miguel Yuaynnes de Necuesa, quienes abandonaron la fuerza que el Infante Luis conducía en apoyo a Pedro I de Castilla en la expedición de Murviedro de $1363^{62}$. En 1378, se registra la de Johan Ramíriz d'Areyllano, hijo, quien en el mes de mayo disponía de una fuerza de 30 hombres de armas ${ }^{63}$, pero que se pasó a los castellanos antes de lá ruptura de hostilidades, al lado de su padre que ya habia abrazado la causa castellana ${ }^{64}$.

El último de los riesgos de la guerra que debía de afrontar un combatiente y el más importante de ellos, era la muerte. A pesar de la eficacia de la protección de las nuevas armaduras y de la preferencia de hacer prisioneros para poder cobrar un rescate, la muerte seguía siendo compañera del guerrero, en especial entre las gentes de a pie, que no entraban en el juego de los rescates por dinero. En lo que se refiere a Navarra, pocas son las referencias de que disponemos acerca de la muerte en combate, aparte de la descripción de la derrota de Cocherel, batalla en la que entre otros muchos navarros pereció Jean de Saut, vasco de Marvail, disponemos de la información de como el prior de Arróniz, Pierres de Garsel, entregó 50 florines de la Tesorería del Reino a Pero Martíniz, señor de Leet, en Labourd-Lapurdi, para el entierro de cuatro de sus compañeros, muertos en servicio del Rey durante los primeros meses de la guerra contra Castilla de 1378-1379 ${ }^{65}$.

A pesar de todos estos riesgos la guerra era tan atractiva para los nobles navarros que no se limitaron a participar tan sólo en las de su

61 AGN, Caj. 36, núm. 25, VI; CASTRO, XI, núm. 525.

${ }^{62}$ AGN, Reg. 104, fol. 136v. AGN, Reg. 107, fol. 177. J. ZaBALO, «Participación navarra en la guerra de los dos Pedros. La expedición a Murviedro de 1363", Homenaje a José Maria Lacarra. Príncipe de Viana. Anejo 3. Tomo II. Pampiona 1986, pág. 781, n. 20 y 21.

63 AGN, Reg. 161, fol. 75v.

64 C. Orcastegul, Crónica de Garci López de Roncesvalles. Estudio y edición crítica. Pamplona, Universidad de Navarra, 1978, pág. 93.

${ }_{65}$ A. PAuPHILET (Compilador). Historiens et chroniqueurs du Moyen Age. Gallimard. Paris 1952, pág. 396 y ss. AGN, Caj. 34, núm. 18; CAStro, XI, núm. 624. 
señor natural, sino que se hizo frecuente el marchar a las campañas europeas en busca de fortuna. Así, cuando en 1357 se preparaba una expedición a Normandía, Martín de Larramendi fue enviado a Gascuña para requerir a los navarros que allí estaban en el servicio inglés para que se uniesen a ella ${ }^{66}$. En 1361, Arnalt Arremón, señor joven de Agramont y merino de Estella, marchó en auxilio del conde de Foix, cuñado de Carlos II, en su conflicto con el conde d'Armagnac ${ }^{67}$. Otros dos señores navarros buscaron su fortuna en Castilla y Aragón al calor de la guerra de los dos Pedros y el conflicto civil castellano, se trataba de Remir Sánchiz, señor de Asiain ${ }^{68}, y$, especialmente, Johan Ramiriz d'Areyllano, quien arrastró consigo a su hijo de igual nombre ${ }^{69}$. Sin lugar a dudas, la más famosa de las intervenciones de los navarros fuera de sus fronteras tuvo lugar en Albania y Grecia, donde acudió una compañia de 123 hombres de armas navarros en auxilio del Infante Luis, duque consorte de Durazzo, para el que conquistaron el ducado balcánico, y a cuya muerte se apoderaron de áreas del Peloponeso y Beocia, a donde habían acudido como soldados de fortuna ${ }^{70}$. Fue asi como los nobles del Reino de Navarra hallaron y explotaron una forma de hacer frente a la crisis de sus ingresos convencionales en la segunda mitad del siglo xIV.

${ }^{66}$ AGN, Reg. 83, fol. 86r.

57 AGN, Caj. 14, núm. 69, II; CASTRO, III, núm. 736. AGN, Caj. 14, núm. 69, VIII; CASTRO, III, núm. 808.

${ }^{68}$ C. Orcastegul, obra citada, pág. 93.

69 P. LOPEZ DE AyalA, obra citada, págs. 530, 552, 557. P. LOPEZ DE AyalA, Crónica del Rey don Enrique II. Madrid, Biblioteca de Autores Españoles, 1953, págs. 29-31.

${ }^{70}$ AGN, Reg. 153 , fol. 33v a 35r. 